\title{
Humoral Response after Vaccination with Half-Dose of BNT162b2 in Subjects under 55 Years of Age
}

\author{
Krzysztof Lukaszuk $^{1,2}$, Amira Podolak ${ }^{1, *(1)}$, Grzegorz Jakiel ${ }^{3}{ }^{\circledR}$, Jolanta Kiewisz ${ }^{4}(\mathbb{D}$, \\ Izabela Woclawek-Potocka ${ }^{5}$ (D), Aron Lukaszuk ${ }^{1,3}$ and Lukasz Rabalski ${ }^{6, *(D)}$ \\ 1 Invicta Research and Development Center, 81-740 Sopot, Poland; luka@gumed.edu.pl (K.L.); \\ lukaszuk.aron@gmail.com (A.L.) \\ 2 Department of Obstetrics and Gynecology Nursing, Medical University of Gdansk, 80-210 Gdansk, Poland \\ 3 The Center of Postgraduate Medical Education, 1st Department of Obstetrics and Gynecology, \\ University of Gdansk, 01-004 Warsaw, Poland; grzegorz.jakiel1@o2.pl \\ 4 Department of Human Histology and Embryology, Medical Faculty, Collegium Medicum, \\ University of Warmia and Mazury in Olsztyn, 10-082 Olsztyn, Poland; jolanta.kiewisz@uwm.edu.pl \\ 5 Department of Gamete and Embryo Biology, Institute of Animal Reproduction and Food Research, \\ Polish Academy of Sciences, 10-748 Olsztyn, Poland; i.woclawek-potocka@pan.olsztyn.pl \\ 6 Laboratory of Recombinant Vaccines, Intercollegiate Faculty of Biotechnology, University of Gdansk, \\ 80-307 Gdansk, Poland \\ * Correspondence: amira.podolak@invicta.pl (A.P.); lukasz.rabalski@biotech.ug.edu.pl (L.R.)
}

check for updates

Citation: Lukaszuk, K.; Podolak, A.; Jakiel, G.; Kiewisz, J.; Woclawek-

Potocka, I.; Lukaszuk, A.; Rabalski, L. Humoral Response after Vaccination with Half-Dose of BNT162b2 in Subjects under 55 Years of Age. Vaccines 2021, 9, 1277. https://doi.org/10.3390/ vaccines 9111277

Academic Editors: Ralph A. Tripp, Steven B. Bradfute and Scott Anthony

Received: 15 September 2021

Accepted: 31 October 2021

Published: 4 November 2021

Publisher's Note: MDPI stays neutral with regard to jurisdictional claims in published maps and institutional affiliations.

Copyright: (c) 2021 by the authors. Licensee MDPI, Basel, Switzerland. This article is an open access article distributed under the terms and conditions of the Creative Commons Attribution (CC BY) license (https:/ / creativecommons.org/licenses/by/ $4.0 /)$.

\begin{abstract}
In the context of the ongoing COVID-19 pandemic, using a half-dose schedule vaccination can help to return to normalcy in a cost-efficient manner, which is especially important for low and middle-income countries. We undertook a study to confirm that in adults up to 55 years old, the humoral response to the half-dose $(15 \mu \mathrm{g}$, 35 participants between 18 and 55 years old) and to the recommended dose ( $30 \mu \mathrm{g}, 155$ participants) in the two-dose three-week interval schedule would be comparable. Antibody levels were measured by the Elecsys Anti-SARS-CoV-2 S assay (Roche Diagnostics, upper detection limit: $2570 \mathrm{BAU} / \mathrm{mL}$ ) on the day of dose 2 of the vaccine and then 8-10 days later to assess peak response to dose 2 . The difference in proportions between the participants who did and did not exceed the upper detection limit 8-10 days after dose 2 was not statistically significant $(p=0.152)$. We suggest that a half-dose schedule can help to achieve widespread vaccination coverage more quickly and cheaply.
\end{abstract}

Keywords: SARS-CoV-2; COVID-19; mRNA vaccine

\section{Introduction}

In the context of the ongoing COVID-19 pandemic, rapid vaccination appears to be the only path to the return to normalcy. Several manufacturers began work on their vaccines in January 2020. In November 2020, Pfizer/BioNTech and Moderna announced the first results from the Phase 3 clinical trials showing high vaccine efficacy for the doses that were selected for testing [1,2]. Understandably, the speed of development was of prime importance; the company's and public's funding were at stake. Therefore, successful approval of the selected vaccine variants and doses was of prime importance. The ultimately produced novel mRNA vaccines were characterized by low production costs, high efficiency in triggering the expected humoral response, and tolerable side effects after application [1-4].

However, both undersupply and the high selling prices in low- and middle-income countries require broadening our perspective [5]. The World Health Organization (WHO) highlights the importance of urgent action to boost supply and ensure equitable access for every country [6]. Even though the U.S. and the G7 nations are committing support for global vaccination programs through COVID-19 Vaccines Global Access (COVAX), only $2.5 \%$ of the population in low-income countries have received at least one dose of the SARS-CoV-2 vaccine [7], and less than $1 \%$ are fully vaccinated [6,8]. This program can 
vaccinate approximately $20 \%$ of the population in participating countries by the end of 2021 [9]. This falls far short of the goal of achieving global herd immunity.

Recently, WHO, with the support of the Strategic Advisory Group of Experts (SAGE) in Immunization and its COVID-19 Working Group, published a statement encouraging research in the area of vaccine reduction [10]. Such a dose-reduction strategy has led to the successful vaccination of millions of people in Africa and South America against yellow fever [11]. Thus, as there is an urgent need to re-evaluate the dosing schedules of the available vaccines to achieve the goals of global SARS-CoV-2 elimination or at least the state of cohabitation, we decided to conduct a pilot study giving people under 55 half the recommended standard dose. We aimed to show that in adults up to 55 years old, the humoral response to the half-dose would be comparable with the response to the recommended dose when vaccinated in the prime-boost three-week interval schedule. Moreover, we took into consideration prior COVID-19 infection.

\section{Materials and Methods}

\subsection{Ethical Policy}

Ethical approval was received from the Ethics Committee at the Gdansk Regional Medical Board (No KB-14/21). All participants gave written informed consent for providing blood samples.

\subsection{Vaccination}

The study group received half the recommended dose (i.e., $15 \mu \mathrm{g}, \mathrm{HD}$ ) of the Pfizer/BioNTech BNT162b2 (BNT162b2) vaccine twice, at an interval of 21 days. The control group was vaccinated using the recommended dose of $30 \mu \mathrm{g}$ (RD) of BNT162b2, separated by a 21-day interval.

\subsection{Participants}

The HD group consisted of 42 people. Among the HD group, 7 subjects reported prior COVID-19 infections confirmed with a PCR test, and 2 had a positive result with a measurable antibodies level before the first dose of the vaccine. Those participants $(n=9)$ were included in the subgroup of participants with prior COVID-19 infection (HDCOVID-19-positive). The remaining 33 subjects were classified as HD-COVID-19-negative. In 5 cases with COVID-19 confirmed by PCR assay, we retrieved archived material for virus sequencing.

The RD group consisted of 188 healthcare professionals who were vaccinated as part of the national vaccination program. Among them, 31 individuals had a history of COVID-19 infection before vaccination (RD-COVID-19-positive). The participants who reported no history of COVID-19 but had a positive antibody test before vaccination $(n=5)$ were also included in the RD-COVID-19-positive subgroup. The RD-COVID-19-negative subgroup included 152 subjects. In 27 cases from the RD-COVID-19-positive subgroup, we were able to obtain sample material for virus sequencing.

The characteristic of attendees and the inclusion and exclusion criteria are presented in Tables 1 and 2, respectively.

Table 1. Characteristic of participants.

\begin{tabular}{ccccc}
\hline Variables & $\begin{array}{c}\text { Number of } \\
\text { Participants }\end{array}$ & $\begin{array}{c}\text { Analyzed } \\
\text { GroupMale/Female }\end{array}$ & Mean Age & Mean BMI \\
\hline Positive & 36 & RD group $(n=188)$ & $38.9(10.9)$ & $24.8(4.7)$ \\
Negative & 152 & $9 / 27$ & $38.7(10.5)$ & $24.3(5.2)$ \\
\hline & & $27 / 125$ & \\
Positive & 9 & HD group $(n=42)$ & $35.1(9.0)$ & $25.0(4.8)$ \\
Negative & 33 & $3 / 6$ & $39.3(8.8)$ & $23.8(4.6)$ \\
\hline
\end{tabular}


Table 2. The inclusion and exclusion criteria of HD and RD groups of BNT162b2 vaccinated people under 55 years of age.

\begin{tabular}{cc}
\hline Inclusion Criteria & Exclusion Criteria \\
\hline Age between 18 and 55 years old & Diabetes \\
Willingness to participate in the study & Hypertension \\
& Heart-disease \\
& Chronic pulmonary disease \\
& Severe allergies \\
& Obesity (BMI $>30)$ \\
\hline
\end{tabular}

The patients' recruitment and study protocol are presented in Figure 1.

\section{ENROLLMENT}
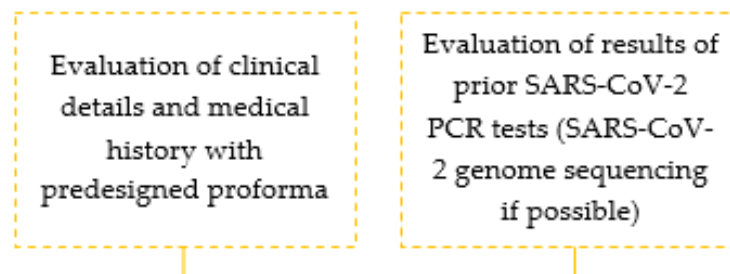

THE TRIAL

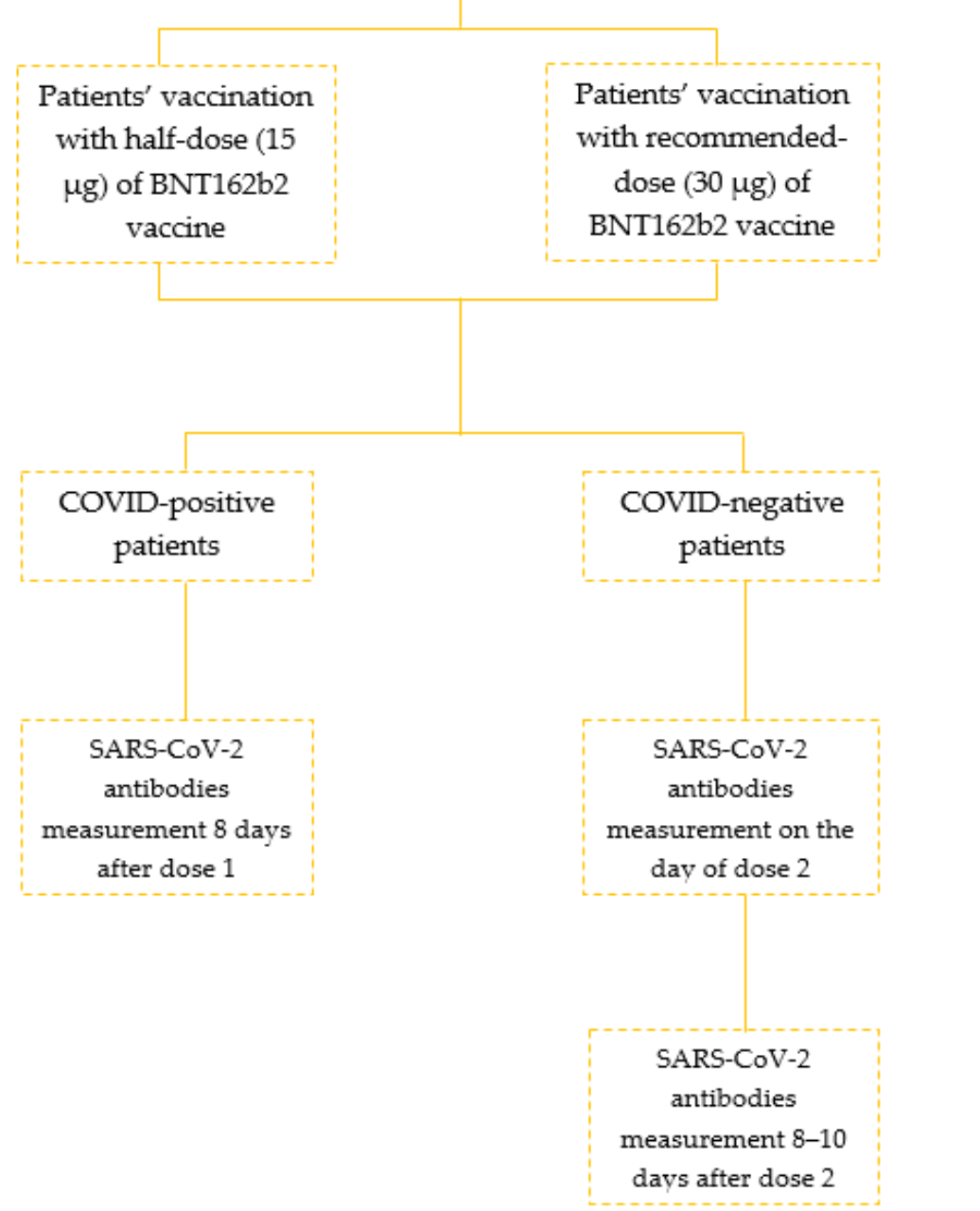

Figure 1. The flow-chart of patients' recruitment and study protocol. 


\subsection{SARS-CoV-2 Antibodies Measurement}

All participants had the initial measurement of their level of SARS-CoV-2 antibodies on the first day of the vaccine dose.

The subjects included in the COVID-19-positive subgroups were retested 8 days after the first dose. The 8-day interval was chosen, based on our previous studies, where we found that the peak patient response to the second dose is achieved on day 8 after vaccination (unpublished data). Other studies [12] show that in individuals who had a prior SARS-CoV-2 infection, the response to the first vaccine dose is similar to the reaction to the second vaccine dose in those without an infection history. The participants who were not affected with COVID-19 infection were examined 21 days after the first dose (i.e., on the day of the second vaccine dose), and then 8 days after the second dose, when the expected humoral response is highest.

\subsection{Assay Characteristics}

Antibody levels were measured by the Elecsys Anti-SARS-CoV-2 S assay (Roche Diagnostics, Switzerland) (Roche). This assay is intended for the quantitative determination of IgG and IgM high-affinity antibodies against SARS-CoV-2 spike (S) protein receptorbinding domain (RBD) in human serum and plasma.

This is an automated assay certified for in vitro diagnostic (IVD) clinical use. The assay is based on the electro-chemiluminescence immunoassay (ECLIA) method and the double-antigen sandwich assay test principle. Two-point calibration is recommended for each new reagent lot and whenever the control results exceed the specified limits. It was initially standardized against the manufacturer's internal standard, and then from 12 January 2021, standardized against WHO International Standard NIBSC20-136. The assay requires $12 \mu \mathrm{L}$ of serum collected using standard testing tubes. Testing time is $18 \mathrm{~min}$.

The test results are reported in units per $\mathrm{mL}(\mathrm{U} / \mathrm{mL})$ and can be converted to the WHO standard, defined as Binding Antibody Units per $\mathrm{mL}(\mathrm{BAU} / \mathrm{mL})$, by multiplying the Roche result by 1.029, according to the manufacturer. As suggested previously [13], the identifiers should be added to the unit designation to show what is being measured. Therefore, for the Roche assay, we described the unit as BAU $\mathrm{RBD}_{\mathrm{IgG}+\mathrm{IgM}} / \mathrm{mL}$. The assay's limit of detection (LoD) is $0.36 \mathrm{BAU} \mathrm{RBD}_{\mathrm{IgG}+\mathrm{IgM}} / \mathrm{mL}$, the limit of quantification (LoQ) is $0.41 \mathrm{BAU} \mathrm{RBD}_{\mathrm{IgG}+\mathrm{IgM}} / \mathrm{mL}$. The measurement range is $0.41-257 \mathrm{BAU}_{\mathrm{RBD}-\mathrm{IgG}+\mathrm{IgM}} / \mathrm{mL}$, and up to $2570 \mathrm{BAU} \mathrm{RBD}_{\mathrm{R}-\mathrm{IgG}+\mathrm{IgM}} / \mathrm{mL}$ for 10 -fold diluted samples.

\subsection{Sequencing}

Viral RNA was extracted from oropharyngeal and nasal swabs collected and stored in viral transport medium in consonance with WHO and CDC recommendations [14,15], using a CoV RNA kit (A\&A Biotechnology), according to the manufacturer's instructions. Nucleic acid amplification testing (NAAT) was performed using a reverse transcriptase real time-PCR kit (genesig ${ }^{\circledR}$ by Primerdesign Ltd., Southampton, UK), CE-IVD marked, for detecting the RdRp gene. RT-PCR is considered the gold standard for the identification of the SARS-CoV-2 virus [16-18]. According to different studies, the Coronavirus COVID-19 genesig ${ }^{\circledR}$ Real-Time PCR assay exhibits $95-100 \%$ clinical sensitivity and $100 \%$ clinical specificity $[19,20]$. The Foundation for Innovative New Diagnostics (FIND), in their comparative LOD study, reports that the test achieved the highest LOD banding (1-10 copies/reaction) [19]. Moreover, the test shows no cross-reactivity with other confirmed respiratory viral infections, such as influenza virus type A, RSV A and B, and rhinovirus [21]. To validate the obtained results, positive and negative controls were included every time the test was conducted. Furthermore, internal RNA extraction control was used as a positive control for the extraction process. Successful qPCR of the exogenous source of the RNA template, spiked into samples during RNA extraction, additionally indicated that the PCR inhibitors were not present at a high concentration.

ARTICv3 amplicon generation, followed by an Oxford Nanopore Technology MinION run, was performed for COVID-19 positive patient samples. RNA was converted to 
cDNA with the RT-PCR technique, using the LunaScript ${ }^{\circledR}$ RT SuperMix Kit (New England BioLabs Inc., Ipswich, UK). Then, the obtained cDNA was amplified to prepare libraries for nanopore sequencing. Amplification was performed using $Q 5^{\circledR}$ Hot Start High-Fidelity $2 X$ Master Mix (New England BioLabs Inc., Ipswich, UK) for two reactions per sample with thermocycling conditions customized to primers' melting temperatures. The concentration of the PCR products was measured with the Qubit 1x dsDNA HS (High-Sensitivity) Assay Kit (ThermoFisher, Waltham, MA, USA). All samples were barcoded and multiplexed together. Then, the AMII adapter ligation reaction was performed using Quick T4 DNA Ligase (New England BioLabs Inc., Ipswich, UK). Final library dilution was prepared with sequencing buffer and loading beads (Oxford Nanopore Technologies, Oxford, UK). To monitor contamination, NRT controls were processed through reactions. Reads were base-called, de-barcoded, and trimmed to remove the adapter, barcode, and PCR primer sequences. ARCTIC pipeline software was used to generate the SARS-CoV-2 genome (ARTIC-nCoV-bioinformaticsSOP-v1.1.0).

\subsection{Statistical Analysis}

Statistical analyses were performed using $\mathrm{R}$ packages (tidyverse). The Wilcoxon signed-rank test was used to assess the differences in mean antibody levels.

\section{Results}

\subsection{The Comparison of Mean Antibody Level in the Serum of COVID-19 Positive Subjects}

There were no statistical differences between mean antibody levels in the serum of participants of the HD-COVID-19-positive (50.8 BAU $\mathrm{RBD}-\mathrm{IgG}+\mathrm{IgM} / \mathrm{mL} ; n=9)$ and RDCOVID-19-positive group (44.1 BAU $\mathrm{RBD}_{\mathrm{IgG}+\mathrm{IgM}} / \mathrm{mL} ; n=36$ ) before vaccination. At this point in time, more than $80 \%$ of participants had antibody levels in the range of

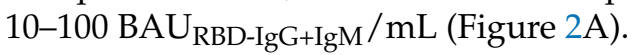

Most test results obtained on day 8 and day 21 after the first dose of the vaccine exceeded the upper detection limit of the Roche assay. The breakdown of the results from day 8 after the first vaccine dose is shown in Figure 2B.

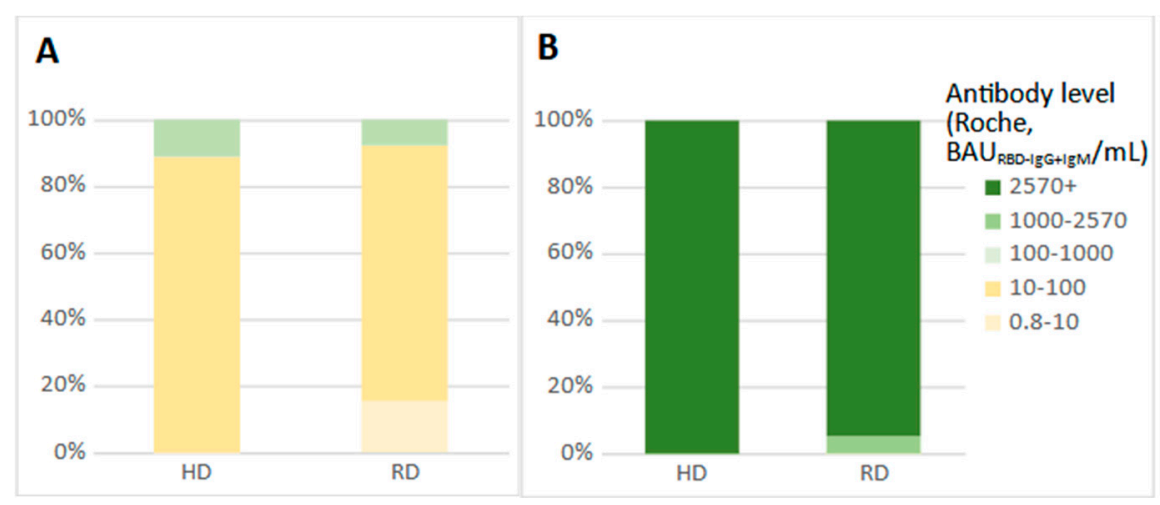

Figure 2. Comparison of antibody levels in the HD- and RD-COVID-19-positive subgroups before vaccination (A) and 8 days after the first vaccine dose (B).

\subsection{The Mean Antibody Level in the Serum of COVID-19 Negative Subjects}

Participants of the HD- and RD-COVID-19-negative subgroups had a negative antibody test result before the first dose of the vaccine. Their first post-vaccination measurement time-point was 21 days after the first dose of the vaccine (i.e., on the day of the second dose). The mean antibody level in the HD-COVID-19 negative group was 82.2 $\mathrm{BAU}$ RBD-IgG+IgM $\mathrm{mL}$, and in the RD-COVID-19 negative group, was $113 \mathrm{BAU} \mathrm{RBD}_{\mathrm{R}-\mathrm{IgG}+\mathrm{IgM}} / \mathrm{mL}$ (Figure 3). The detection limit of the Roche kit was exceeded 8-10 days after the second dose in $58 \%$ of the participants in the HD-COVID-19 negative group, and $70 \%$ of the RD-COVID-19 negative group. The difference in proportions between the participants who did and did not exceed the detection limit 8-10 days after dose 2 was not 
statistically significant $(p=0.152)$. Mean antibody levels for participants who did not exceed the 2570 RBD-IgG+IgMmL detection limit were 1300 RBD-IgG+IgM/mL $(n=14)$ and

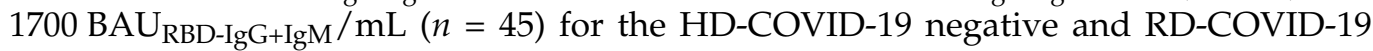
negative subgroups, respectively
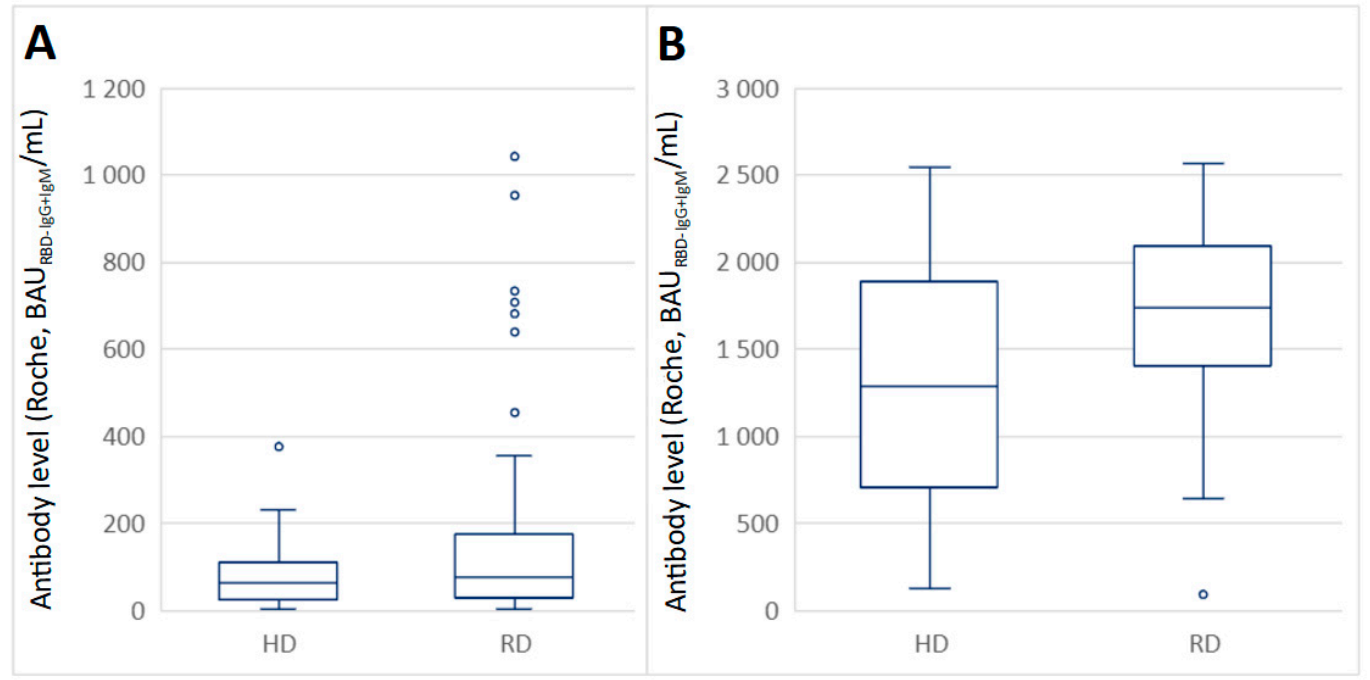

Figure 3. Boxplot (median, hinges: first and third quartiles, whiskers: the largest value no further than 1.5 * IQR from the hinge) showing humoral response to the vaccination as measured with antibody levels in the RD- and HD-COVID-19negative subgroups on the day of the second dose (FD: $n=152$, HD: $n=33$; (A) and 8-10 days after the second dose for participants whose results were within the test detection limit (FD: $n=45$, HD: $n=14 ;(B)$ ).

\section{Discussion}

The current study compares the humoral response to the half-dose and recommended dose of the vaccine administrated to adults up to 55 years old. A strong humoral response was observed 8 days after the first dose of vaccine in the group of subjects with previous COVID-19 infection. Participants in both the RD and HD group who did not have COVID19 disease, showed a weaker reaction in response to the first dose of the BNT162b2 vaccine, and had a peak humoral response 8 days after the second vaccine dose with the majority exceeding the upper test detection limit. We observed no differences between the mean antibody levels in the serum of the RD and HD groups of COVID-19 negative subjects. It seems that there were no differences in humoral response between the groups vaccinated with the half-dose and the recommended dose.

In addition, pre-vaccination results showed that $3 \%$ of subjects did not know they were infected with SARS-CoV-2.

Pfizer/BioNTech, during phase 1 of the vaccine preparation trial, excluded all participants with prior infection, confirmed not only by positive PCR but also serologically $[1,3]$. While in the Moderna vaccine trial, subjects with a history of disease were allowed to participate [2]. It should be kept in mind that including such participants in the analysis may bias the results. On the other hand, their participation in such a study provided proof of a much higher immunological response in previously infected individuals due to the previous contact with the pathogen $[12,22,23]$.

Interestingly, the humoral response after the first dose in the HD group was comparable to the response observed in the RD group. Both immune reactions did not achieve a level that significantly reduces the risk of infection. However, the priming dose of the vaccine elicits a response that sets the stage for a robust and faster reaction to subsequent contact with the antigen. Therefore, individuals infected with a low dose of the virus are capable of a response that prevents the virus from breaking through the immune system, and thus have a significantly lower risk of severe infection or death [24]. Instead, they 
provide a transmission link for the disease. However, exposure to a large dose of the virus after a single dose of the vaccine may not give the infected person time for a secondary response. Hence, frequent cases of severe infection after only one dose of the vaccine are observed.

We have showed that administration of a lower dose of vaccines in a group of people younger than 55 years old appears to provide sufficient protection for most people at doses of the virus to which people are exposed, on average. Various vaccine dosing schedules were evaluated during phase 1 of vaccine trials.

Phase 1 of the Pfizer trial compared the immune response with various vaccine doses between participants 18-55 and 65-85 years of age. Each group included 15 participants, with three receiving the placebo. Their response was compared with the results obtained from the serum of COVID-19 convalescent donors (serum was obtained at least 14 days after diagnosis was confirmed by a PCR test). For each tested vaccine dose, the immune response measured by the antibody and neutralization assays was lower in the older group. It appears that the $30 \mu \mathrm{g}$ dose was selected as it was the only dose in the 65-85 group where the response of the trial participants exceeded the COVID-19 convalescent results. However, the results for the younger group after the second dose of the vaccine exceeded the COVID-19 convalescent results in all tested vaccine doses at $10 \mu \mathrm{g}, 20 \mu \mathrm{g}$, and $30 \mu \mathrm{g}[1,3,4,25,26]$.

In our study, all participants with a history of prior SARS-CoV-2 infection had antibody assay results above the detection range of the test after the first dose of the vaccine, in both the half-dose and the recommended dose groups. Other studies have also shown that vaccine recipients with prior infection react to the first vaccine dose similarly to how those who were not infected respond to the second dose [12].

Moderna's phase 1 trial of the mRNA-1273 vaccine in the 18-55-year-old population included 45 participants divided into three groups for the tested doses of $25 \mu \mathrm{g}, 100 \mu \mathrm{g}$, and $250 \mu \mathrm{g}$ [27]. The additional expanded trial of adults older than 55 years of age, had 40 participants divided into four groups based on age (56-70 and $\geq 71$ years old) and dose $(25 \mu \mathrm{g}$ and $100 \mu \mathrm{g})$. In both parts of the trial, participants were not screened for a history of SARS-CoV-2 infection. It is clearly noted in the expanded portion of the trial that includes participants over 55 years of age, that antibodies against SARS-CoV-2 RBD were found in the serum before the vaccination [2]. Therefore, the mean response in each group depended not only on the vaccine dose but also on the number of participants with prior infection.

Moreover, 7 months after the first administration of the $25 \mu \mathrm{g}$ dose in Phase 1 of the Moderna trial, Mateus et al. [28] examined vaccine-specific CD4+ T cells, CD8+ T cells, and binding antibody and neutralizing antibody responses. Six months after the second dose, nearly all of the 35 participants had neutralizing antibodies blocking the virus from infecting cells, and levels of both antibodies and T cells were comparable to those induced by natural infection. In addition, the Moderna mRNA-1273 vaccine is currently undergoing studies using a half-dose for booster doses, but data are not yet available [10].

The AstraZeneca phase 1 trial focused on comparing a single dose schedule with the prime-boost schedule (COOV1). Exclusion criteria included prior confirmed COVID-19 infection, but as the serology testing was not available, some participants included in the study had likely undergone the infection asymptomatically. It was noted in the study results that some participants exhibited high levels of neutralizing antibodies at baseline, thus skewing the results obtained. In the case of AstraZeneca, the lower vaccine dose was tested in phase 2 and phase 3 trials, as a result of the difference in the measurement of viral particles used in the manufacturing process. Due to the discovered differences, additional study groups were formed for participants who received the lower dose (LD) as the first dose, and the standard dose (SD) as the second dose. The interim trial analysis has shown the efficacy to be higher in the LD/SD group than in the SD/SD group $[29,30]$.

The limitation of our study is the lack of evaluation of antibody levels in a longer follow-up period. However, when compared to the Moderna trial, it is promising that the protection may be the same as the recommended dose. Still, even if the immune responses to the low-dose strategy may only be moderately effective, it could be worth speeding up 
the pace of vaccination as fractionated doses could provide a feasible solution that extends limited supplies of vaccines against COVID-19, which is a major challenge for low- and middle-income countries [31]. According to the Wiecek et al. [32] modelling study, the low-dose strategy would reduce infections and COVID-19 linked deaths more than current policies. For the mRNA-1273 vaccine, the model proposed by Khoury et al. [33] suggests that if vaccine efficacy at the complete dose is $95 \%$, a reduction in the dose that led to as much as a halving in the post-vaccination geometric mean titer could still be in the range of $85-90 \%$. To our knowledge, there is one trial ongoing in Belgium comparing the lower dose version $(20 \mu \mathrm{g})$ of the Pfizer/BioNTech vaccine versus the standard dose in healthy adults up to 55 years of age. The study completion date is estimated to be 30 September 2022 [34].

Another limitation is that we do not know how high antibody levels would need to be to sufficiently have the effect of neutralizing the virus and blocking it from entering the host cell and multiplying. However, the data already available show that it correlates with measured levels of binding antibodies [35,36]. Although research on the WHO International Standard introduced the goal of standardizing the results obtained with different SARSCoV-2 antibody assays and correlating their level with the neutralizing effect, this has not been confirmed in previous studies $[13,23]$. The dangers of new mutations escaping the neutralizing properties of antibodies formed both after COVID-19 and after vaccination, should be the impetus to vaccinate the maximum possible proportion of the population as soon as possible, to obtain the maximum possible neutralizing antibody levels in that population. This is to not only reduce the disease mortality but also to limit its spread and minimize the time and population space for the virus to mutate $[37,38]$.

\section{Conclusions}

We believe that using a half-dosage schedule could be one way to increase vaccine supply and to accelerate population-level vaccination coverage in low- and middle-income countries to reduce mortality, as was demonstrated in the past with the yellow fever vaccine.

The study needs to be conducted on a larger group with a longer follow-up period. On the other hand, the results of the study that administered a third dose (i.e., booster), may nullify the need for additional studies and point us in the direction of vaccinating those receiving half a dose with a booster after a specified interval. The third dose may, presumably, be even less than half of the currently administered dose.

Author Contributions: Conceptualization, K.L.; methodology, K.L., A.P., G.J., L.R.; formal analysis, K.L., A.L.; investigation, K.L.; data curation, A.L.; writing-original draft preparation, K.L., A.P.; writing-review and editing, K.L., A.P., G.J., J.K., I.W.-P., A.L., L.R.; visualization A.L.; supervision, K.L., L.R.; project administration, K.L. All authors have read and agreed to the published version of the manuscript.

Funding: This research received no external funding.

Institutional Review Board Statement: The studies were conducted according to the guidelines of the Declaration of Helsinki and approved by the Ethics Committee at the Gdansk Regional Medical Board (No KB-4/21 and KB-14/21).

Informed Consent Statement: Informed consent was obtained from all subjects involved in the study.

Data Availability Statement: The data presented in this study are available on request from the corresponding author.

Conflicts of Interest: The authors declare no conflict of interest.

\section{References}

1. Polack, F.P.; Thomas, S.J.; Kitchin, N.; Absalon, J.; Gurtman, A.; Lockhart, S.; Perez, J.L.; Marc, G.P.; Moreira, E.D.; Zerbini, C.; et al. Safety and efficacy of the BNT162b2 mRNA Covid-19 vaccine. N. Engl. J. Med. 2020, 383, 2603-2615. [CrossRef] [PubMed]

2. Anderson, E.J.; Rouphael, N.G.; Widge, A.T.; Jackson, L.A.; Roberts, P.C.; Makhene, M.; Chappell, J.D.; Denison, M.R.; Stevens, L.J.; Pruijssers, A.J.; et al. Safety and Immunogenicity of SARS-CoV-2 mRNA-1273 Vaccine in Older Adults. N. Engl. J. Med. 2020, 383, 2427-2438. [CrossRef] 
3. Mulligan, M.J.; Lyke, K.E.; Kitchin, N.; Absalon, J.; Gurtman, A.; Lockhart, S.; Neuzil, K.; Raabe, V.; Bailey, R.; Swanson, K.A.; et al. Phase I/II study of COVID-19 RNA vaccine BNT162b1 in adults. Nature 2020, 586, 589-593. [CrossRef] [PubMed]

4. Walsh, E.E.; Frenck, R.W., Jr.; Falsey, A.R.; Kitchin, N.; Absalon, J.; Gurtman, A.; Lockhart, S.; Neuzil, K.; Mulligan, M.J.; Bailey, R.; et al. Safety and Immunogenicity of Two RNA-Based Covid-19 Vaccine Candidates. N. Engl. J. Med. 2020, 383, $2439-2450$. [CrossRef] [PubMed]

5. Ahmed, S.; Khan, S.; Imran, I.; Al Mughairbi, F.; Sheikh, F.; Hussain, J.; Khan, A.; Al-Harrasi, A. Vaccine Development against COVID-19: Study from Pre-Clinical Phases to Clinical Trials and Global Use. Vaccines 2021, 9, 836. Available online: https:/ / www.mdpi.com/2076-393X/9/8/836 (accessed on 19 August 2021). [CrossRef]

6. WHO. Vaccine Inequity Undermining Global Economic Recovery. 2021. Available online: https://www.who.int/news/item/22 -07-2021-vaccine-inequity-undermining-global-economic-recovery (accessed on 19 August 2021).

7. Ritchie, H.; Mathieu, E.; Rodés-Guirao, L.; Appel, C.; Giattino, C.; Ortiz-Ospina, E.; Hasell, J.; MacDonald, B.; Beltekian, D.; Dattani, S.; et al. Coronavirus Pandemic (COVID-19). Our World in Data. 2020. Available online: https:// ourworldindata.org/ covid-vaccinations (accessed on 3 November 2021).

8. Maxmen, A. The Fight to Manufacture COVID Vaccines in Lower-Income Countries. Nature 2021, 597, 455-457. Available online: https: / / www.nature.com/articles/d41586-021-02383-z (accessed on 19 August 2021). [CrossRef] [PubMed]

9. Mullard, A. How COVID vaccines are being divvied up around the world. Nature 2020. [CrossRef] [PubMed]

10. WHO. Interim Statement on Dose-Sparing Strategies for COVID-19 Vaccines (Fractionated Vaccine Doses). 2021. Available online: https: / / www.who.int/news/item/10-08-2021-interim-statement-on-dose-sparing-strategies-for-covid-19-vaccines(fractionated-vaccine-doses) (accessed on 15 October 2021).

11. Casey, R.M.; Harris, J.B.; Ahuka-Mundeke, S.; Dixon, M.G.; Kizito, G.M.; Nsele, P.M.; Umutesi, G.; Laven, J.; Kosoy, O.; Paluku, G.; et al. Immunogenicity of Fractional-Dose Vaccine during a Yellow Fever Outbreak—Final Report. N. Engl. J. Med. 2019, 381, 444-454. [CrossRef] [PubMed]

12. Ebinger, J.E.; Fert-Bober, J.; Printsev, I.; Wu, M.; Sun, N.; Prostko, J.C.; Frias, E.C.; Stewart, J.L.; Van Eyk, J.E.; Braun, J.G.; et al. Antibody responses to the BNT162b2 mRNA vaccine in individuals previously infected with SARS-CoV-2. Nat. Med. 2021, 27, 981-984. [CrossRef]

13. Lukaszuk, K.; Kiewisz, J.; Rozanska, K.; Dabrowska, M.; Podolak, A.; Jakiel, G.; Woclawek-Potocka, I.; Lukaszuk, A.; Rabalski, L. Usefulness of IVD Kits for the Assessment of SARS-CoV-2 Antibodies to Evaluate the Humoral Response to Vaccination. Vaccines 2021, 9, 840. [CrossRef]

14. Laboratory Testing of 2019 Novel Coronavirus (2019-nCoV) in Suspected Human Cases: Interim Guidance, 17 January 2020. Available online: https:/ / www.who.int/publications/i/item/laboratory-testing-of-2019-novel-coronavirus-(-2019-ncov)-insuspected-human-cases-interim-guidance-17-january-2020 (accessed on 19 August 2021).

15. CDC Labs. Available online: https://www.cdc.gov/coronavirus/2019-ncov/lab/lab-biosafety-guidelines.html?CDC_AA_refVal= https $\% 3 \mathrm{~A} \% 2 \mathrm{~F} \% 2 \mathrm{Fwww} . c d c . g o v \% 2 F c o r o n a v i r u s \% 2 F 2019-$ ncov\%2Flab-biosafety-guidelines.html (accessed on $13 \mathrm{July} 2021$ ).

16. Oliveira, B.A.; de Oliveira, L.C.; Sabino, E.C.; Okay, T.S. SARS-CoV-2 and the COVID-19 disease: A mini review on diagnostic methods. Rev. Inst. Med. Trop. Sao Paulo. 2020, 62, 1-8. [CrossRef]

17. Younes, N.; Al-Sadeq, D.W.; Al-Jighefee, H.; Younes, S.; Al-Jamal, O.; Daas, H.I.; Yassine, H.M.; Nasrallah, G.K. Challenges in Laboratory Diagnosis of the Novel Coronavirus SARS-CoV-2. Viruses 2020, 12, 582. [CrossRef]

18. Chau, C.H.; Strope, J.; Figg, W.D. COVID-19 Clinical Diagnostics and Testing Technology. Pharmacother. J. Hum. Pharmacol. Drug Ther. 2020, 40, 857-868. [CrossRef] [PubMed]

19. Oladimeji, P.; Pickford, J. Letter of concern re: “Comparison of seven commercial RT-PCR diagnostic kits for COVID-19" van Kasteren et al., Journal of Clinical Virology. J. Clin. Virol. 2020, 130, 104536. Available online: https: / / europepmc.org/articles/ PMC7336925 (accessed on 19 August 2021). [CrossRef] [PubMed]

20. Carter, N.; Clausen, M.; Halpin, R.A.; Blackmore, C.; Cai, K.; Delpuech, O.; Kohlmann, A.; Magnusson, O.; March, R.; O’Neill, D.; et al. A novel automated SARS-CoV-2 saliva PCR test protects a global asymptomatic workforce. Sci. Rep. 2021, 11, 1-6. [CrossRef]

21. van Kasteren, P.B.; van der Veer, B.; van den Brink, S.; Wijsman, L.; de Jonge, J.; van den Brandt, A. Comparison of seven commercial RT-PCR diagnostic kits for COVID-19. J. Clin. Virol. 2020, 128, 104412. [CrossRef] [PubMed]

22. Abbasi, J. Study Suggests Lasting Immunity after COVID-19, with a Big Boost from Vaccination. JAMA 2021, 326, 376-377. [CrossRef] [PubMed]

23. Perkmann, T.; Perkmann-Nagele, N.; Koller, T.; Mucher, P.; Radakovics, A.; Wolzt, M.; Wagner, O.F.; Binder, C.J.; Haslacher, H. Serum antibody response to BNT162b2 after natural SARS-CoV-2 infection. Eur. J. Clin. Investig. 2021, 51, e13632. [CrossRef] [PubMed]

24. Dopico, X.C.; Ols, S.; Loré, K.; Hedestam, G.B.K. Immunity to SARS-CoV-2 induced by infection or vaccination. J. Intern. Med. 2021. Available online: https:/ / onlinelibrary.wiley.com/doi/10.1111/joim.13372 (accessed on 19 August 2021). [CrossRef]

25. Study to Describe the Safety, Tolerability, Immunogenicity, and Efficacy of RNA Vaccine Candidates Against COVID-19 in Healthy Individuals. Available online: https:/ / clinicaltrials.gov/ct2/show / NCT04368728 (accessed on 19 August 2021).

26. Pfizer-BioNTech COVID-19 BNT162b2 Vaccine Effectiveness Study-Kaiser Permanente Southern California. Available online: https:/ / clinicaltrials.gov / ct2/ show / NCT04848584?term=pfizer\&draw=2\&rank=1 (accessed on 19 August 2021). 
27. Jackson, L.A.; Anderson, E.J.; Rouphael, N.G.; Roberts, P.C.; Makhene, M.; Coler, R.N.; McCullough, M.P.; Chappell, J.D.; Denison, M.R.; Stevens, L.J.; et al. An mRNA Vaccine against SARS-CoV-2-Preliminary Report. N. Engl. J. Med. 2020, 383, $1920-1931$. [CrossRef] [PubMed]

28. Mateus, J.; Dan, J.M.; Zhang, Z.; Moderbacher, C.R.; Lammers, M.; Goodwin, B.; Sette, A.; Crotty, S.; Weiskopf, D. Low dose mRNA-1273 COVID-19 vaccine generates durable T cell memory and antibodies enhanced by pre-existing crossreactive $\mathrm{T}$ cell memory. medRxiv 2021, preprint. [CrossRef]

29. Folegatti, P.M.; Ewer, K.J.; Aley, P.K.; Angus, B.; Becker, S.; Belij-Rammerstorfer, S.; Bellamy, D.; Bibi, S.; Bittaye, M.; Clutterbuck, E.A.; et al. Safety and immunogenicity of the ChAdOx1 nCoV-19 vaccine against SARS-CoV-2: A preliminary report of a phase 1/2, single-blind, randomised controlled trial. Lancet 2020, 396, 467-478. [CrossRef]

30. Voysey, M.; Clemens, S.A.C.; Madhi, S.A.; Weckx, L.Y.; Folegatti, P.M.; Aley, P.K.; Angus, B.; Baillie, V.L.; Barnabas, S.L.; Bhorat, Q.E.; et al. Safety and efficacy of the ChAdOx1 nCoV-19 vaccine (AZD1222) against SARS-CoV-2: An interim analysis of four randomised controlled trials in Brazil, South Africa, and the UK. Lancet 2020, 397, 99-111. [CrossRef]

31. Dolgin, E. Quarter-dose of Moderna COVID vaccine still rouses a big immune response. Nat. Cell Biol. 2021. Available online: http:/ / www.nature.com/articles/d41586-021-01893-0 (accessed on 15 October 2021). [CrossRef]

32. Więcek, W.; Ahuja, A.; Kremer, M.; Gomes, A.S.; Snyder, C.; Tabarrok, A.; Tan, B.J. Could Vaccine Dose Stretching Reduce COVID-19 Deaths? 2021. Available online: https:/ / www.ssrn.com/abstract=3864485 (accessed on 15 October 2021).

33. Khoury, D.S.; Cromer, D.; Reynaldi, A.; Schlub, T.E.; Wheatley, A.K.; Juno, J.A.; Subbarao, K.; Kent, S.J.; Triccas, J.A.; Davenport, M.P. Neutralizing antibody levels are highly predictive of immune protection from symptomatic SARS-CoV-2 infection. Nat. Med. 2021, 27, 1205-1211. [CrossRef]

34. COVID-19: Safety and Immunogenicity of a Reduced Dose of the BioNTech/Pfizer BNT162b2 Vaccine (REDU-VAC). Available online: https: / / clinicaltrials.gov/ct2/show / NCT04852861 (accessed on 19 August 2021).

35. Dispinseri, S.; Secchi, M.; Pirillo, M.F.; Tolazzi, M.; Borghi, M.; Brigatti, C.; De Angelis, M.L.; Baratella, M.; Bazzigaluppi, E.; Venturi, G.; et al. Neutralizing antibody responses to SARS-CoV-2 in symptomatic COVID-19 is persistent and critical for survival. Nat. Commun. 2021, 12, 2670. [CrossRef]

36. Gilbert, P.B.; Montefiori, D.C.; McDermott, A.; Fong, Y.; Benkeser, D.C.; Deng, W.; Zhou, H.; Houchens, C.R.; Martins, K.; Jayashankar, L.; et al. Immune Correlates Analysis of the mRNA-1273 COVID-19 Vaccine Efficacy Trial. medRxiv. 2021. Available online: https:/ / www.medrxiv.org/content/early/2021/08/15/2021.08.09.21261290 (accessed on 19 August 2021).

37. Garcia-beltran, W.F.; Lam, E.C.; Denis, K.S.; Nitido, A.D.; Zeidy, H. Multiple SARS-CoV-2 variants escape neutralization by vaccine-induced humoral immunity. Cell 2021, 184, 2372-2383. [CrossRef]

38. Hacisuleyman, E.; Hale, C.; Saito, Y.; Blachere, N.E.; Bergh, M.; Conlon, E.G.; Schaefer-Babajew, D.J.; DaSilva, J.; Muecksch, F.; Gaebler, C.; et al. Vaccine Breakthrough Infections with SARS-CoV-2 Variants. N. Engl. J. Med. 2021, 384, 2212-2218. [CrossRef] 